\title{
Thermal and Physico-Mechanical Properties of Irradiated Aluminum Oxide-Filled Ethylene Propylene Diene Monomer Rubber Composites
}

\author{
Rania Mounir, Maysa A. Mohamed, Mai. M. EL-Zayat \\ Radiation Chemistry Department, National Center for Radiation Research and Technology, Egyptian Atomic Energy Authority, \\ Cairo, Egypt.
}

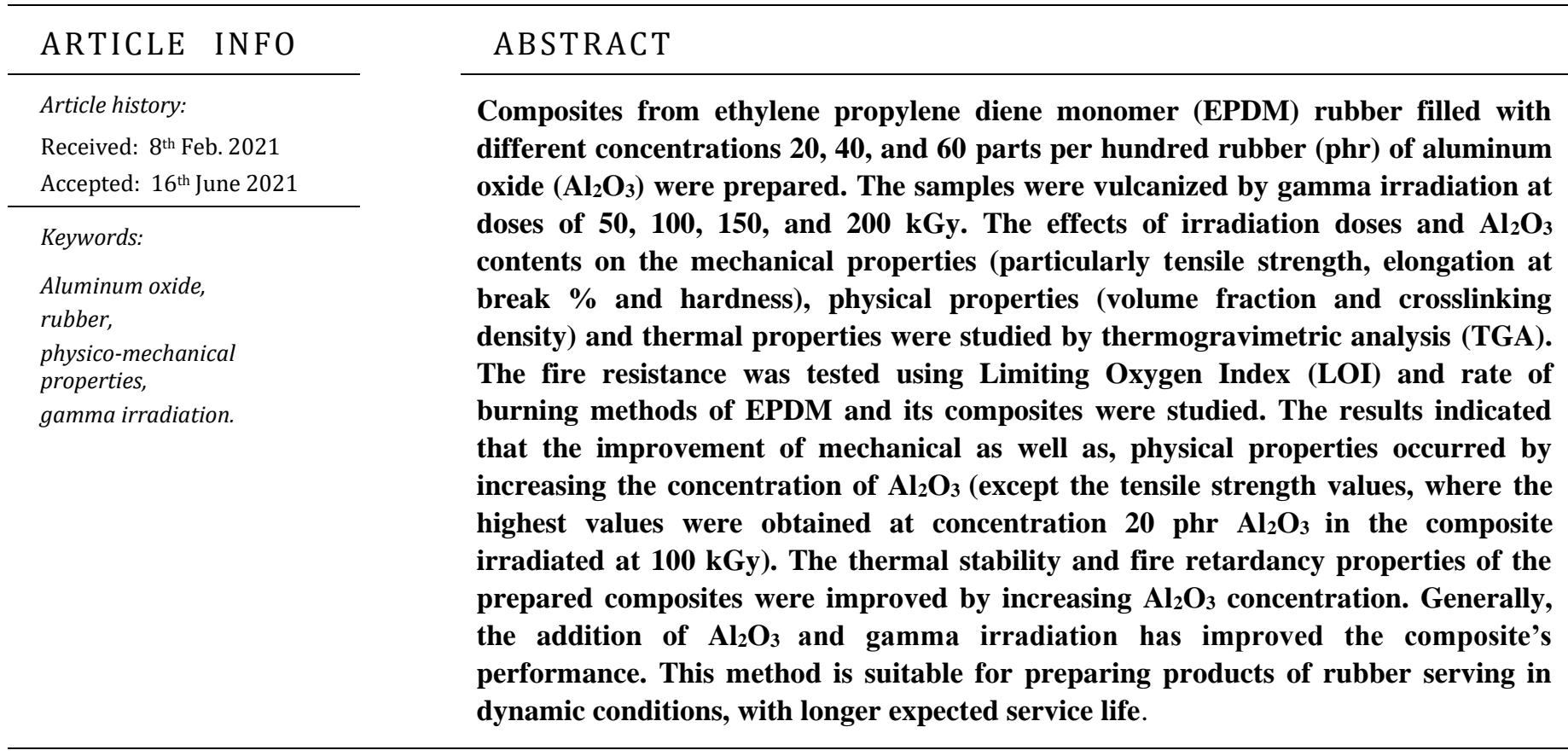

\section{1-INTRODUCTION}

One of the fastest developing synthetic rubbers in the market is ethylene-propylene-diene rubber (EPDM) for broad purposes and special applications. EPDM chains with saturated backbone and non-polar structure gives this material an outstanding electrical resistivity. [1]

In general, due to rubber's excellent elasticity, it usually works within the dynamic serving conditions like: rubber roller, rubber transmission, tire belt, etc., rubber reinforcement is very important and essential to satisfy the useful applications. [2]

EPDM is usually utilized in various fields due to its distinctive properties such as ozone resistance, climate change mitigation, , and wonderful insulating properties, all this makes it used in automobile manufacturing, construction, cable manufacture. Conversely, EPDM is awfully flammable which limits its application in several areas and leaves safety risk without suitable treatment of flame-retardant. In recent years, the researches worked on the improvement of the flame retardant EPDM composite. Aluminum hydroxide trihydrate or magnesium hydroxide is the most common metal hydroxides that functions across dehydration to $\mathrm{Al}_{2} \mathrm{O}_{3}$ or $\mathrm{MgO}$. A fire-retardant composite can be produced by addition of $\mathrm{Al}$ trihydrate to polymers to decrease temperature of surface by taking the heat created through burning away. [3]

Rubber and other polymer compounds combustion represent a severe oxidation reaction in the air. So, to increase flame resistance, the flame retardant was added into the rubber cable materials. $\mathrm{Al}_{2} \mathrm{O}_{3}$, which is used in industrial applications, can be added to the polymer as a flame retardant material to improve the flame retardancy characteristics of polymers. [4-6]. Furthermore, $\mathrm{Al}_{2} \mathrm{O}_{3}$ is used in the piping parts production like elbows, tees, straight pipes etc. Additional applications include the manufacture of many machining tools, thermocouple sheaths and wear-resistant pump impellers. [7] 
In the processing of polymers, the utilization of radiation is gaining more attention as it may be investigated as a different method to the classical chemical methods to modify polymer's molecular structure. A new opportunity to obtain well-tailored materials can be achieved by radiation processing possibility of the polymers in the solid state.

Macroscopic changes in a new composite's properties formation may be caused by gamma irradiation. Some radiation-induced variation in the chemical structure of EPDM composites may be the cause of the changes in its properties. The alteration nature may differ according to the irradiation dose.

This study aimed at the preparation of irradiated flame retardant composites based on EPDM rubber and $\mathrm{Al}_{2} \mathrm{O}_{3}$ as flame retardant reinforcing filler with good mechanical, physical and thermal properties which is suitable for preparing products of rubber serving in dynamic conditions, with the longer expected service life.

\section{2-EXPERIMENTAL}

\subsection{Materials}

EPDM rubber, with $59 \%$ of ethylene content and $4.4 \%$ of 5-ethylidene-2-norboreneas termonomer was purchased by Italian Polimer Europa with commercial name (Dutral*TER 4049) Mooney viscosity $\left(\mathrm{ML}_{1+4}, 125^{\circ} \mathrm{C}\right)$ 76. $\mathrm{Al}_{2} \mathrm{O}_{3}$ (Alumina), usually known as aluminum oxide was purchased from Montplet and Estaban SA Barcelona-Espana, is an inert, odorless, white amorphous material. Zinc Oxide $(\mathrm{ZnO})$ appears as white powder, provided by EL-Nasr Chemical Company. (Egypt). Stearic acid was purchased from China, m.p.: $54^{\circ} \mathrm{C}$.

\subsection{Preparation of composites}

Raw EPDM, $\mathrm{Al}_{2} \mathrm{O}_{3}(20,40,60) \mathrm{phr}, \mathrm{ZnO}$ and Stearic acid, were mixed with the rubber in a roll-mill at $25{ }^{\circ} \mathrm{C}$. Table (1) shows the components of the samples. All samples were pressed by an electric hot press type Carver-M-154at $160{ }^{\circ} \mathrm{C}$, 5min preheating and at 20,000 PSI for $10 \mathrm{~min}$ then cooling of samples occur for $5 \mathrm{~min}$ at the similar pressure.
Table (1): composition of samples

\begin{tabular}{lcccc}
\hline Ingredient & A & B & C & D \\
\hline EPDM & 100 & 100 & 100 & 100 \\
$\mathrm{Al}_{2} \mathrm{O}_{3}$ & 0 & 20 & 40 & 60 \\
$\mathbf{Z n O}$ & 5 & 5 & 5 & 5 \\
Stearic acid & 1 & 1 & 1 & 1 \\
\hline
\end{tabular}

\subsection{Gamma irradiation}

All samples were irradiated by $\gamma$-radiation at doses of 50, 100, 150 and $200 \mathrm{kGy}$ (Indian $\gamma$ cell type 4000A) in air and ambient humidity at room temp. The dose rate is $1.1 \mathrm{kGy} / \mathrm{h}$. The samples were then prepared for different measurements by cutting into specimens. Irradiation was carried out at National Center for Radiation Research and Technology (NCRRT), Egyptian Atomic Energy Authority (AEA), Cairo, Egypt.

\section{3-MEASUREMENTS}

\subsection{Mechanical properties}

Mechanical tests such as tensile strength (TS), elongation at break \% $\left(\mathrm{E}_{\mathrm{b}} \%\right)$ and hardness (shore $\mathrm{A}$ ) were done at room temperature. Each point of the data is the average of 5 measurements along the sample.

For TS and $\mathrm{E}_{\mathrm{b}} \%$, according to ASTM D 412A, Model 10-I mecmesin equipped with software was utilized employing $500 \mathrm{~mm} / \mathrm{min}$ crosshead speed. Different mechanical parameters were calculated in this system. The samples were dumbbell shaped with $4 \mathrm{~mm}$ width and $50 \mathrm{~mm}$ length for TS and $\mathrm{E}_{\mathrm{b}} \%$ measurements.

For hardness test, samples with flat surface with $1 \mathrm{~mm}$ thickness were cut. According to ASTM D2240, a durometer of model 306L type A was used for the measurement. The hardness unit is expressed in (Shore A).

\subsection{Physical measurements.}

\subsubsection{Volume fraction of rubber in a swollen gel.}

Volume fraction expresses the fraction of insoluble weight of the sample after being extracted. Samples of the irradiated blend were accurately weighed in special glass thimbles. The thimbles were then placed in the 
siphon tube of the extraction apparatus (Soxhlet). The condenser, siphon tube and flasks are placed together and toluene was added. Heating was carried out and regulated, then the extraction was continued for 24 hours. After extraction, the samples were dried to a constant weight in vacuum at about $40^{\circ} \mathrm{C}$;

According to the following equation, rubber volume fraction was calculated in a swollen gel $\left(\mathrm{V}_{\mathrm{r}}\right)$,

$\mathrm{V}_{\mathrm{r}}=\left[\left(\mathrm{W}_{1}-\mathrm{W}_{\mathrm{o}} \mathrm{f}\right) / \delta_{\mathrm{r}}\right] /\left[\left(\mathrm{W}_{1}-\mathrm{W}_{\mathrm{o}} \mathrm{f}\right) / \delta_{\mathrm{r}}+\left(\mathrm{W}_{2}-\mathrm{W}_{1}\right) / \delta_{\mathrm{s}}\right]$

Where, $\mathrm{W}_{0}=$ original weight,

$\mathrm{W}_{1}=$ de-swollen weight (weight after extraction and drying),

$\mathrm{W}_{2}$ =weight after swelling,

$\mathrm{f}=$ weight fraction of insoluble components,

$\delta_{\mathrm{r}}$ and $\delta_{\mathrm{s}}$ the density of the rubber and solvent (toluene), respectively.

\subsubsection{Crosslinking density $(\mathrm{Cd})$ :}

Crosslink density was calculated by equilibrium swelling in toluene, i.e. the network chain density number, Flory-Rehner equation [7] was applied as following:

$\mathrm{Cd}=-1 / \mathrm{V}_{\mathrm{s}}\left\{\left[\ln \left(1-\mathrm{V}_{\mathrm{r}}\right)+\mathrm{V}_{\mathrm{r}}+\mathrm{x}_{1} \mathrm{~V}_{\mathrm{r}}^{2}\right] /\left[\mathrm{V}_{\mathrm{r}}^{1 / 3}-\mathrm{V}_{\mathrm{r}} / 2\right]\right\}$

$\mathrm{V}_{\mathrm{s}}$ :molar volume of the solvent.

$\mathrm{V}_{\mathrm{r}}$ : volume fraction of rubber in the swollen gel.

$\mathrm{X} 1$ : polymer-solvent interaction parameter which is equal to 0.351 for EPDM in toluene.

\subsection{Flammability measurements}

A set of test methods and corresponding standards have been established to distinguish the flame retardancy of materials, the most typical and main test methods containing Limiting Oxygen Index (LOI) and ASTM (D 635) method.

\subsubsection{Limiting Oxygen Index (LOI)}

LOI value is the minimum concentration of oxygen in the $\mathrm{O}_{2} / \mathrm{N}_{2}$ mixture that each maintains the material burning for $3 \mathrm{~min}$. or consumes a $5 \mathrm{~cm}$ length sample. $\mathrm{O}_{2}$ index system instrument, Type HC-2, (Jiangning Instrument Analysis Factory, and Nanjing, China) is used for holding the samples vertically. According to the standard oxygen index, ISO 4589-1984, all tests were carried out. [3]

\subsubsection{Rate of burning}

The burning rate of fabricated composites was obtained by subjecting to the flammability test in a horizontal position according to the ASTM (D 635) method.[8] Linear sheets of composites were cut into bar-shaped test pieces with $125 \times 13 \times 3 \mathrm{~mm}$ dimensions. At least 10 samples were taken for each composite system. The rate of average value of burning was stated in $\mathrm{mm} / \mathrm{min}$.

\subsection{Thermogravimetric analysis}

A TG-50 instrument from Shimadzu (Japan) was used for testing the thermal behavior of the samples. The heating of samples were carried out at temperature range from room temperature to $600{ }^{\circ} \mathrm{C}$ with a heating rate of $10^{\circ} \mathrm{C} / \mathrm{min}$ under nitrogen gas atmosphere. The weight of samples ranged from 3 to $5 \mathrm{mg}$ each.

\section{4-RESULTS AND DISCUSSION.}

\subsection{Mechanical properties.}

The main factors on which the mechanical properties of composites depend are the aspect ratio of the filler, the dispersion degree of the filler in the matrix, and the adhesion at the filler-matrix interface. The effect of the mechanical properties (TS, $\mathrm{E}_{\mathrm{b}} \%$ and hardness) of $\mathrm{Al}_{2} \mathrm{O}_{3}$ loaded EPDM was investigated.

\subsubsection{Tensile strength (TS).}

Figure (1) shows the changes in the TS of unirradiated and irradiated EPDM and its composite loaded with different concentration of $\mathrm{Al}_{2} \mathrm{O}_{3}$.

It is clear from this figure that EPDM rubber demonstrated the minimum TS values either before or after $\gamma$ irradiation. EPDM/20 $\mathrm{phr} \mathrm{Al}_{2} \mathrm{O}_{3}$ has the highest TS values. This is due to homogenous dispersion of the filler inside the rubber formed strong interfacial adhesion between filler and matrix. The results indicate, also that, the TS values of EPDM composites filled with 40 and $60 \mathrm{phr} \mathrm{Al}_{2} \mathrm{O}_{3}$ decrease due to agglomeration of filler in matrix causes weakness in bond between filler and matrix.

It is also shown that the TS values of EPDM and its composites increase with irradiation dose reaching $100 \mathrm{kGy}$ then started to reduce. The reason may be due to the developing crosslink density formed by a combination of free radicals that were generated on virgin EPDM and/or $\mathrm{Al}_{2} \mathrm{O}_{3}$. Whereas the TS values of EPDM and its composites decrease at doses greater than $100 \mathrm{kGy}$ due to degradation process in polymer chain occurs. [3] 


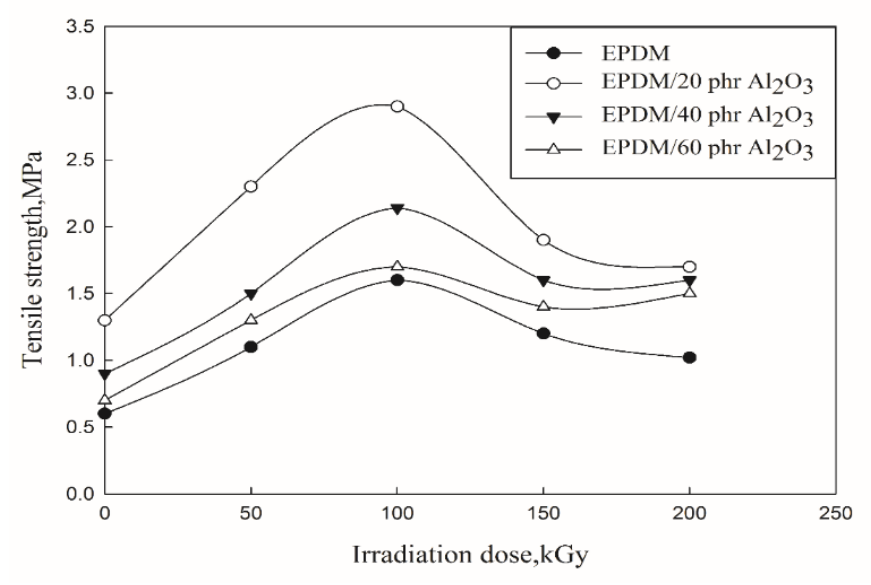

Fig. (1): Effect of gamma irradiation on Tensile strength, on EPDM and its composites filled with different concentrations of $\mathrm{Al}_{2} \mathrm{O}_{3}$

\subsubsection{Elongation at break $\%\left(\mathrm{E}_{\mathrm{b}} \%\right)$}

The percentage of elongation $\left(\mathrm{E}_{\mathrm{b}} \%\right)$ of unirradiated and irradiated EPDM and its composites is described in figure (2).It can be shown that, $E_{b} \%$ of all samples increases with increasing irradiation dose from 0-50 kGy, because of the occurrence of initial crosslinking. After that, at higher irradiation doses, $\mathrm{E}_{\mathrm{b}} \%$ values for all samples decrease due to increasing the crosslinking density with different rates depending on the sensitivity of each composition to the irradiation dose to form free radicals. As a result, the increasing of crosslinking density increased the mobility hindrance of the molecular chains. Also, EPDM rubber possessed the highest values of $\mathrm{E}_{\mathrm{b}} \%$ either it was irradiated or unirradiated, due to its elasticity. Moreover, it was noted that, the $\mathrm{E}_{\mathrm{b}} \%$ values decrease, as the $\mathrm{Al}_{2} \mathrm{O}_{3}$ concentration increases. The decrease in $\mathrm{E}_{\mathrm{b}} \%$ is due to the overload of $\mathrm{Al}_{2} \mathrm{O}_{3}$ that reduces and restricts the EPDM chains mobility and consequently decreases the flexibility of chains. This tested data was supported with the previous study. [9-12]

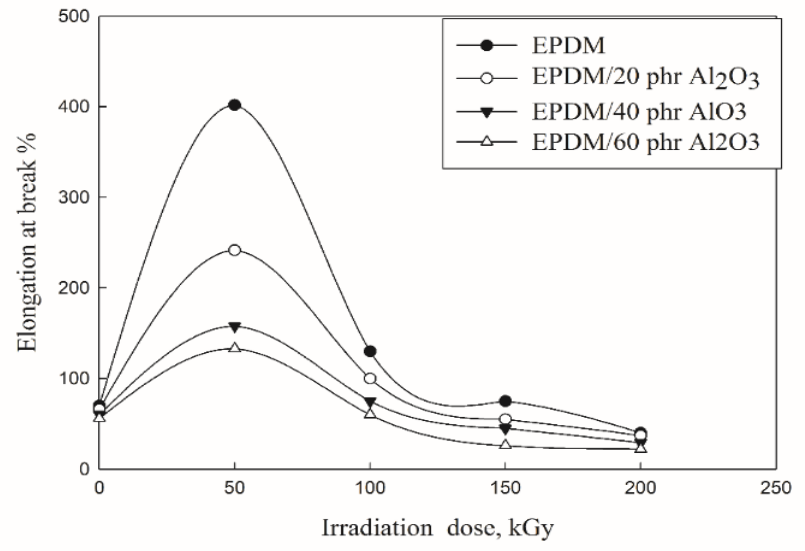

Fig. (2): Effect of gamma irradiation on Elongation at break $\%$ on EPDM and its composites filled with different concentrations of $\mathrm{Al}_{2} \mathrm{O}_{3}$

\subsubsection{Hardness (Shore A)}

Figure (3) demonstrates the hardness of unirradiated and irradiated EPDM and its composites filled with different concentrations of $\mathrm{Al}_{2} \mathrm{O}_{3}$. It is obvious that the hardness values of the samples increase with increasing $\mathrm{Al}_{2} \mathrm{O}_{3}$ loading and irradiation dose. This is due to the the decrease in the polymer chains elasticity with the theincrease of the filler particles loaded in the soft matrix, resulting in more rigid composites. [13-15]. These rigid fillers make composites harder than the unfilled polymer and make the polymer composites more resistance to any penetration for any foreign body.

Also, the hardness of irradiated composites is higher than that of unirradiated one, due to the crosslinking formation leading to more rigid surface.[16]

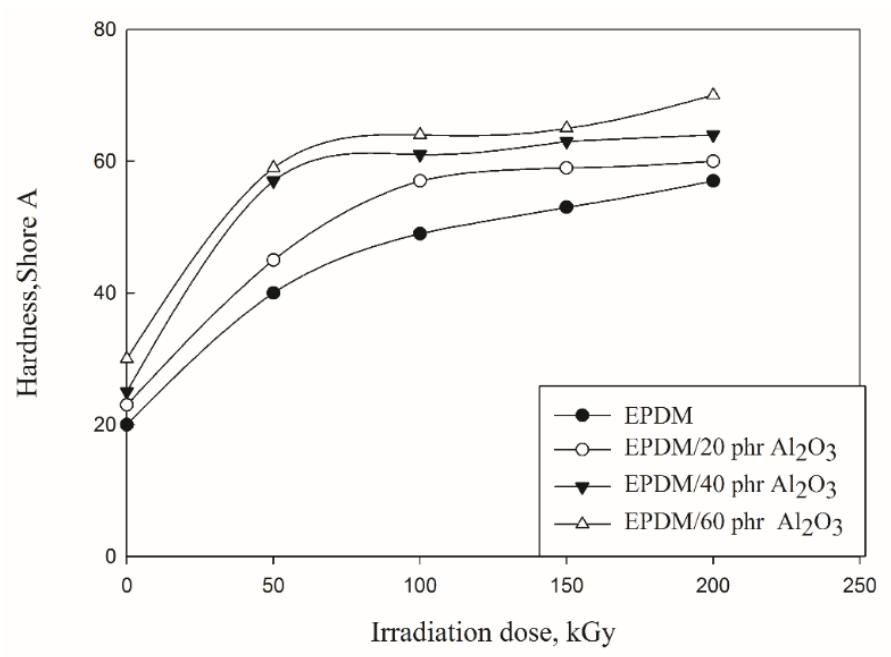

Fig. (3) Effect of gamma irradiation on Hardness on EPDM and its composites filled with different concentrations of $\mathrm{Al} 2 \mathrm{O3}$

\subsection{Physical properties}

Both volume fraction and crosslinking density measurements can be used to indicate irradiationinduced crosslinking. The volume fraction and crosslinking density variation with different doses of radiation for the pristine EPDM and its composites with different concentrations of $\mathrm{Al}_{2} \mathrm{O}_{3}$ are shown in Figures (4 and 5) respectively. Generally, it can be noticed that, the volume fraction and the crosslinking density increase as the load ratio of $\mathrm{Al}_{2} \mathrm{O}_{3}$ and radiation dose increase up to $200 \mathrm{kGy}$.

The dispersion of $\mathrm{Al}_{2} \mathrm{O}_{3}$ within the matrix explains this phenomenon. The free radicals were created in the rubber matrix by radiation dose that strengthens the three-dimensional network, i.e., crosslinking density, between the $\mathrm{Al}_{2} \mathrm{O}_{3}$ and rubber matrix (physical bonds), 
thus leading to a decrease in the pores number, and as a result, the penetration of toluene therein decreases. Additionally, the filler concentrations are not the only parameter that affected the stiffness of composites, but also the surface area of the filler. Although, high filler concentrations has a high surface area value, agglomeration of particles can be produced due to reduction of the inter-particle distance in which lots of particles stick together and do not disperse properly. In this case, the exposed filler surface area is reduced. [17]

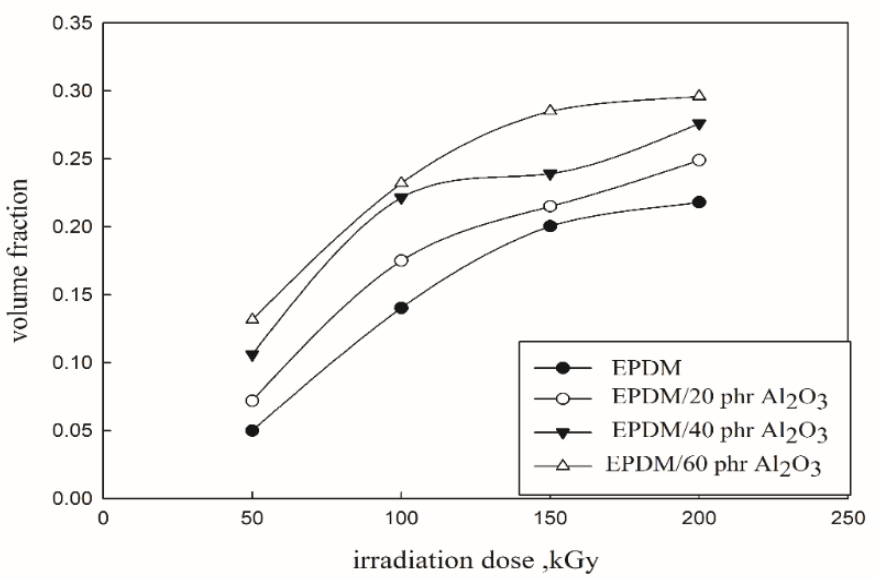

Fig. (4) Effect of gamma irradiation on volume fraction of EPDM and its composites filled with different concentrations of $\mathrm{Al}_{2} \mathrm{O}_{3}$

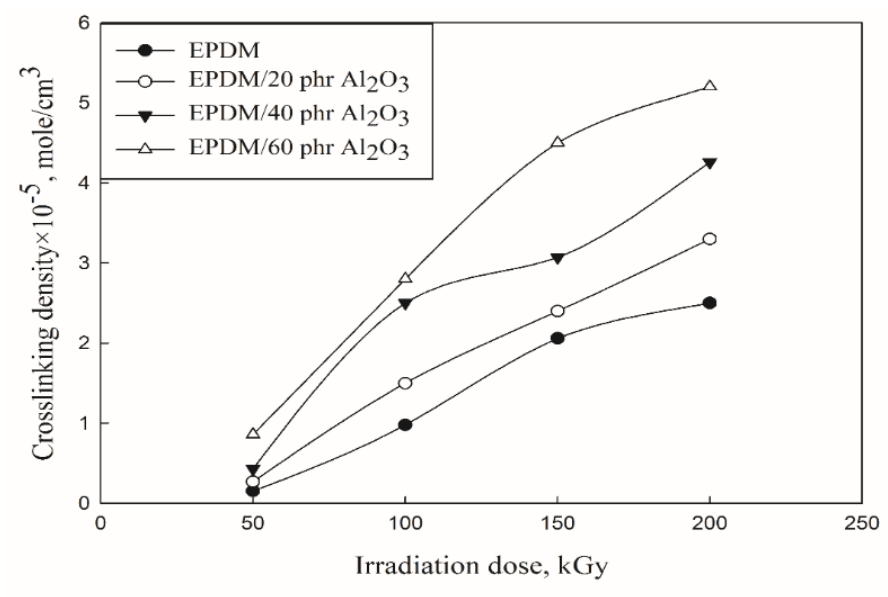

Fig (5) Effect of gamma irradiation on crosslinking density of EPDM and its composites filled with different concentrations of $\mathrm{Al}_{2} \mathrm{O}_{3}$

\subsection{Flammability measurements.}

\subsubsection{Limiting Oxygen Index (LOI)}

Polymers are known for their comparatively high flammability. In many features, the polymers combustion is similar to several other solid materials combustion. But the polymers tendency to spread flame away from a fire source is critical as the tendency of several polymers to melt and to produce flows or flammable drips. Consequently, testing the flammability of polymer products under conditions near to those of the final application or when assembled with another materials is always important. LOI has been considered to calculate flame retardant properties of polymer materials. In this experiment, LOI values of irradiated samples at $100 \mathrm{kGy}$ are shown in Figure (6) the observations are in accordance with, as the content of applied inorganic flame-retardant $\mathrm{Al}_{2} \mathrm{O}_{3}$ increased, the LOI of the irradiated composites increase compared with the LOI value of EPDM. The influence of $\mathrm{Al}_{2} \mathrm{O}_{3}$ on the flame-retardancy of the composites may be attributed to the fact that $\mathrm{Al}_{2} \mathrm{O}_{3}$ forms a protective gas layer which is a thick membrane that inhibits the volatilization of and prevent diffusion of oxygen into the polymer matrix, thus retarding polymer matrix burning $[3,8]$

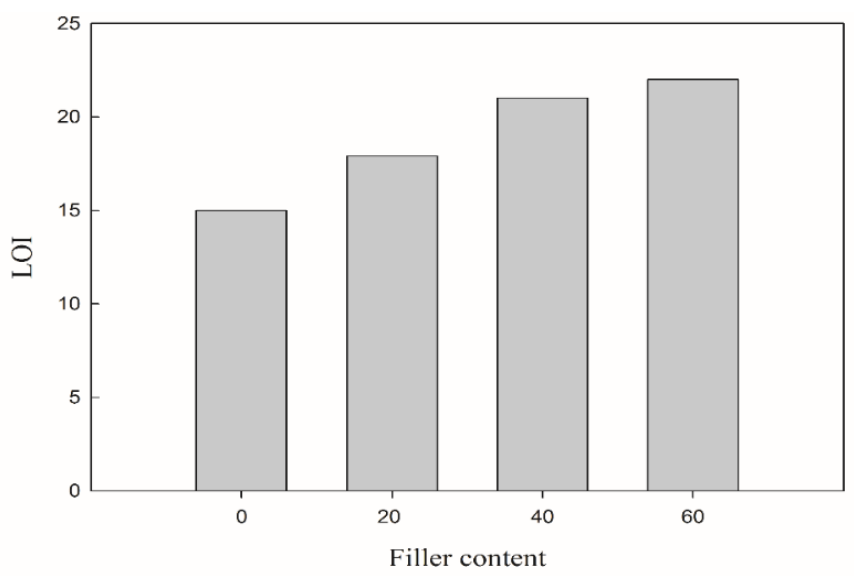

Fig. (6) Effect of $\mathrm{Al}_{2} \mathrm{O}_{3}$ filler concentrations on $\mathrm{LOI}$ of EPDM and its composites at 100kGy

\subsubsection{Rate of burning}

The rate of burning of irradiated EPDM and its composites (at $100 \mathrm{kGy}$ ) is clearly shown in Table (2). Addition of $\mathrm{Al}_{2} \mathrm{O}_{3}$ as flame resistantfiller affects the EPDM composites flammability. The results in Table (2) show that the burning rate is enhanced after the incorporation of $\mathrm{Al}_{2} \mathrm{O}_{3}$ into EPDM with respect to the virgin EPDM. As $\mathrm{Al}_{2} \mathrm{O}_{3}$ concentration increases, the burning rate decreases because $\mathrm{Al}_{2} \mathrm{O}_{3}$ is a dense membrane which can hinder the volatilization of gas and prevent diffusion of oxygen into the polymer matrix, thus retarding polymer matrix burning i.e. The $\mathrm{Al}_{2} \mathrm{O}_{3}$ layer is cutting down the supply of $\mathrm{O}_{2}$ and the decomposed organic products into combustion zone. [18].

Table (2): Rate of Burning of irradiated EPDM and its composites at $100 \mathrm{kGy}$

\begin{tabular}{lc}
\hline Sample code & Burning rate $(\mathrm{mm} / \mathrm{min})$ \\
\hline EPDM & 11 \\
EPDM/20 phr $\mathrm{Al}_{2} \mathrm{O}_{3}$ & 6.5 \\
EPDM/40 phr $\mathrm{Al}_{2} \mathrm{O}_{3}$ & 4.5 \\
EPDM/60 phr $\mathrm{Al}_{2} \mathrm{O}_{3}$ & 2 \\
\hline
\end{tabular}

Arab J. Nucl. Sci. Appl., Vol. 54, 4, (2021) 


\subsection{Thermogravimetric analysis (TGA)}

TGA is a technique which can be utilized to determine the thermal stability of the polymers and polymer blends [19]. The TGA of irradiated EPDM and its composites at $100 \mathrm{kGy}$ is shown in Figure (7). Whereas Table (3) shows a summary of the TGA results of EPDM and its composites, where $\mathrm{T}_{\text {onset }}$ is the temperature at which the samples start decomposing, $\mathrm{T}_{\text {end }}$ indicates the temperature that the weight loss was completed and the char residue $(\%)$ at $600{ }^{\circ} \mathrm{C}$.

By analyzing Figure (7), it is noticed that there is a slight increase in the $\mathrm{T}_{\text {onset }}$ and $\mathrm{T}_{\text {end }}$.On the other hand, the amount of char residue (\%) increased by increasing the content of $\mathrm{Al}_{2} \mathrm{O}_{3}$ in the composites. $\mathrm{Al}_{2} \mathrm{O}_{3}$ prevents heat from transmitting quickly which limits the decomposition of the composites. This may be due to the fact that $\mathrm{Al}_{2} \mathrm{O}_{3}$ is an inorganic filler having great barrier properties and high thermal stability [20]. It can be observed that at $600^{\circ} \mathrm{C}$, the composite's residual mass \% showed an enhancement upon the loading of $\mathrm{Al}_{2} \mathrm{O}_{3}$ at the maximum cited filler ratio and this may be related to formation of physical bond between EPDM matrix and $\mathrm{AL}_{2} \mathrm{O}_{3}$.

Table (3): Summary of TGA results of irradiated EPDM and its composites at $100 \mathrm{kGy}$

\begin{tabular}{lccc}
\hline Sample ID & $\begin{array}{c}\mathbf{T}_{\text {onset }} \\
\left({ }^{\circ} \mathbf{C}\right)\end{array}$ & $\begin{array}{c}\mathbf{T}_{\text {end }} \\
\left({ }^{\circ} \mathbf{C}\right)\end{array}$ & $\begin{array}{c}\text { Residual mass } \\
\text { \% at 600 }{ }^{\circ} \mathbf{C}\end{array}$ \\
\hline EPDM & 401 & 421 & 21 \\
EPDM/20 phr $\mathrm{Al}_{2} \mathbf{O}_{3}$ & 403 & 426 & 22 \\
EPDM/40 phr $\mathrm{Al}_{2} \mathbf{O}_{3}$ & 405 & 431 & 29 \\
EPDM/60 $\mathbf{~ p h r ~} \mathrm{Al}_{2} \mathbf{O}_{3}$ & 410 & 455 & 35 \\
\hline
\end{tabular}

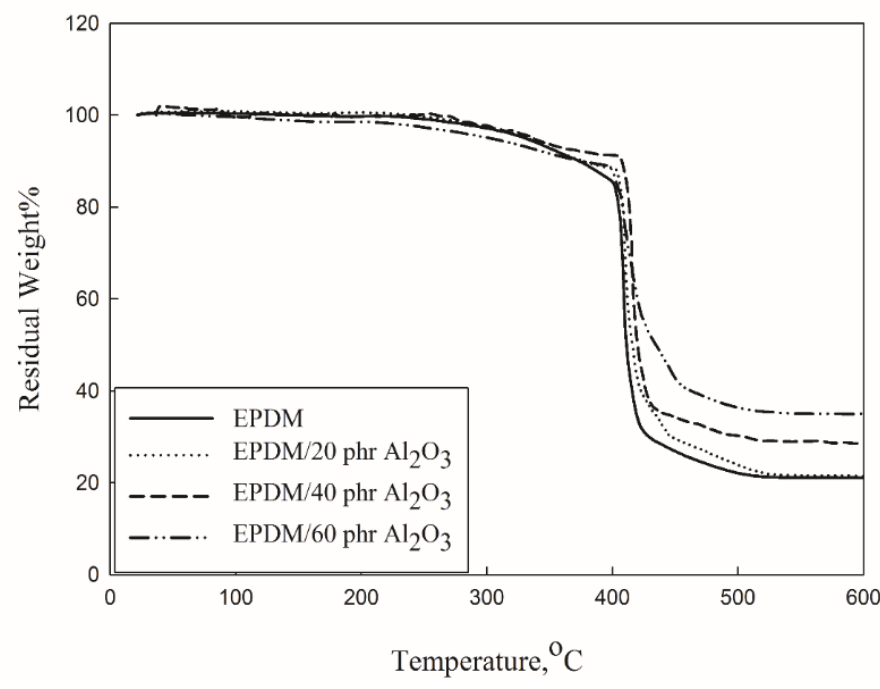

Fig. (7) TGA of EPDM and its composites with different concentrations of $\mathrm{Al}_{2} \mathrm{O}_{3}$ Irradiated at $100 \mathrm{kGy}$

\section{5-CONCLUSIONS}

EPDM rubber is extremely flammable material which limits its application in several fields and represents a safety risk without suitable flame-retardant treatment. Consequently, the development of the EPDM composite must be undertaken.

The most common metal oxides such as aluminum oxide $\left(\mathrm{Al}_{2} \mathrm{O}_{3}\right)$ are incorporated into polymers to produce a fire-retardant composite.

In this work, composites were prepared from EPDM rubber filled with different concentrations $(20,40$, and $60 \mathrm{phr})$ of aluminum oxide $\left(\mathrm{Al}_{2} \mathrm{O}_{3}\right)$. Vulcanization of EPDM and its composites occurred by gamma radiation at 50,100, 150, and $200 \mathrm{kGy}$. Physico-mechanical properties, flammability resistant, and thermal stability of the composites were studied. The results showed that the maximum tensile strength values of samples were at $20 \mathrm{phr}$ of $\left(\mathrm{Al}_{2} \mathrm{O}_{3}\right)$ and $100 \mathrm{kGy}$ radiation dose. Elongation at break \% values decrease as the concentration of $\left(\mathrm{Al}_{2} \mathrm{O}_{3}\right)$ increase. Whereas, the hardness and the physical properties as well as flammability resistant and the composite's thermal stability were enhanced by increasing the concentration of $\left(\mathrm{Al}_{2} \mathrm{O}_{3}\right)$ and radiation doses.

Generally, the addition of $\left(\mathrm{Al}_{2} \mathrm{O}_{3}\right)$ to EPDM rubber and $\gamma$ irradiation improved the mechanical, physical, flame resistant and thermal properties of the composites.

\section{REFERENCES}

[1] Zonghuan, L., Jun, Z., and Shuangjun, C. (2009): "Effect of carbon blacks with various structures on electrical properties of filled ethylene-propylenediene rubber "Journal of Electrostatics 67, 73-75

[2] Zhen-Hua, W., Yong-Lai, L., Jun, L.,Zhi-Min, D.,Li-Qun, Z., and Weimin, W. (2011):"Preparation of nanoalumina/EPDM composites with good performance in thermal conductivity and mechanical properties". Polymer Advenced Technologies, 22, 2302-2310.

[3] 3.Heba, A. R., Mona Y. E., and Fathy, E.S.,(2019):"Flame-Retardancy and PhysicoThermomechanical Properties of Irradiated Ethylene Propylene Diene Monomer Inorganic Composites". Journal of Vinyl and Additive Technology25, 59-67.

[4] Weili, W., and Lei, T. (2012):"Preparation of EPDM Flame-resistant Cable Mater". Applied Mechanics and Materials", 151, 240-244.

[5] Ynh-Yue, Y.,Hsin-Ta, W., and Wen-Jen, G. (2013):"Synergistic Effect of Aluminum Hydroxide 
and Nanoclay on Flame Retardancy and Mechanical Properties of EPDM Composites". Journal of applied polymer science, 130, 20422048.

[6] Anithambigai, P.,Mutharasu, D.,Huong, L. H., Thomas, Z., David, L., and Kamarulazizi, I. (2017):"Improved thermal and mechanical properties of aluminum Oxide filled epoxy composites by reinforcing milled carbon fiber by partial replacement method". Journal of Material Science: Material in Electronics, 28, 13487-13495.

[7] RuysA.J., Alumina Ceramics: Biomedical and Clinical Applications,Elsiver, UK: Wood head Publishing, 2018.

[8] Hamzah, M. S.,and Mariatti, M. (2012):"Properties of flame-retardant fillers in polypropylene/ ethylene propylene diene monomer composites". Journal of Thermoplastic Composite Materials26, 1223-1236

[9] Datta, J., and Głowinska, E. (2011):"Influence of cellulose on mechanical and thermomechanical properties of elastomers obtained from mixtures containing natural rubber"Polimery 11,823-827.

[10] Faruk, O.,Bledzki, A.K., Fink, H.P., and Sain, M. (2012):"Biocomposites Reinforced with Natural Fiber". Progress in Polymer Science 37, 15521596.

[11] Raghavendra, S.,Lingaraju, A.,Shetty, P., and Mukunda, p. (2013):"Mechanical Properties of Short Banana Fiber Reinforced Natural Rubber Composites" International Journal of Innovative Science Engineering and Technology, 2, 1652

[12] El-Nemr, K.F., and Mohamed, R. M. (2017):"Sorbic acid as friendly curing agent for enhanced properties of ethylene propylene diene monomer rubber using gamma radiation". Journal of Macromolecular. Science, Part A Pure and Applied Chemistry, 54, 711-719.

[13] Al-Ghamdi, A.A., El-Tantawy, F., and Abdel, A. N. (2009):"Stability of new electrostatic discharge protection and electromagnetic wave shielding effectiveness from poly (vinyl chloride)/graphite /nickel nanoconducting composites". Polymer Degradation Stability, 94, 980.

[14] Vino, V.S., Varghese, S.,Kuriakose, B., and Varughese, K.T. (2002):"Properties of aluminum powder filled styrene butadiene rubber composites".Kautschuk Gummi Kunststoffe, 55, 512-517

[15] Siddaramaiah, N.M.R., and Sudhakar, R.D. Styrene butadiene rubber/aluminum powder composites mechanical, morphological and electrical behaviors. Journal of Material Science: Material in Electronics. 2007, 18, 635.

[16] Mansour, S. H.,Iskander, B. A., and Nasrat, L. S. (2006):"Effect of Various Temperature Environments on the Performance of PVC/ATH Composites as Insulating Material". PolymerPlastic Technoogy and Engineering, 45, 857-863

[17] Zeinab, F.; Morteza, E.; Samad, M. (2013):"Dynamic mechanical and thermal behavior evaluation of an epoxy/anhydride/nano-aluminum oxide composite system". High Performance Polymer, 25,518-525

[18] Feng, Y., and Gordon, L. N. (2011):"Combination effect of nanoparticles with flame retardants on the flammability of nanocomposites". Polymer Degradation and Stability, 96, 270-276.

[19] Shamshad, A.; Basfar, A.A.; Abdel Aziz, M.M. (2002):"Comparison of thermal stability of sulfur, peroxide and radiation Cured NBR and SBR vulcanizates". Polymer Degradation and Stability, 67, 319-323

[20] Mohamed. M. A.,Hany, A. A., Mona, K. A., and Abdel g. M. R.(2016):"Modification of $\mathrm{CeO}_{2}$ and Its Effect on Physical and Mechanical Properties of Gamma Irradiated EPDM Rubber Nanocomposite Contain Montmorillonite Modified Nano clay". Journal of vinyl\& additive Technology, 23, 201210. 